\title{
Con Goya en el Museo del Prado
}

\author{
Por ALEJANDRO MIRO QUESADA G.
}

Permítanme un breve exordio, a manera de explicación. No habría deseado, -como organizador de éste, hasta ahora, brillante ciclo sobre arte español-, intervenir en él, pero de un lado la gentil solicitud de mi amigo Julio Prieto Nespereira, inmejorable Director de ésta magnífica "Exposición de Goya y el Grabado Español" y de otro el afán, para mí, constante y agudo, de recordar a los limeños, la necesidad de crear un gran museo de pintura, han sido razones más que poderosas, para ofrecer esta conferencia. No tiene ella otro propósito que, evocar la figura de Goya y recorrer junto con ustedes, su valiosa obra en el Museo del Prado. Complementar así, con una visión pictórica, la admirable muestra del Goya grabador, que hoy lucen estos salones, y al hacerlo, comprobar, una vez más, la enorme importancia del Museo, que al través del tiempo $\mathrm{y}$ del espacio, irradiar permanentemente y a miles de kilómetros de distancia, sus bellos y eternos mensajes de arte.

Había otro factor que, por cierto pesó mucho en mí. Aquello de hablar de Goya, rodeado de Goyas. Nunca he tenido oportunidad de hacerlo en un ambiente más adecuado. Estos "proverbios" que nos aguaitan desde la penumbra, y que hablan un lenguaje de iniciados, aquellos "Caprichos", mordaces y punzantes, que lanzan la cruda verdad a la cara, o esos "Desastres de la Guerra", que comprueban, hasta qué grado es falso el concepto del progreso de la humanidad; y cuyos claro-oscuros misteriosos irradian el misterio de la verdad. Verdad misteriosa en lo que tiene de desconocida. ¿Qué es lo real? ¿Es lo formal? ¿Lo que creemos ver? ¿O es la esencia del ser, que muchas veces no vemos...?

Hay figuras, como la de Goya, que para la mejor comprensión de su obra, requiere se escudriñe previamente en su ser. No nos permite el tiempo de esta charla, hacer un estudio completo de su vida. Pero 
sí debemos anotar aunque sea en breves trazos, los rasgos más saltamtes de su recia y multiforme personalidad artística.

Tenemos la suerte de poder conocer la vida de Gcya, por dentro y por fuera, no sólo por lo que de ella hablaron en su tiempo, se dijo y escribió de él, sino, y ello es quizás lo más importante, por las nutridas, socarronas y campechanas cartas que a menudo escribía a su leal y admirable amigo Zapater. Allí, al través de la prosa sencilla y de una peculiar ortografía, tan llena de sinceridad, conocemos al Goya de dentro, el que relata la alegría de sus triunfos y los sinsabores de sus decepciones, la vanidad de los honores y su arrogante independencia y lo que es más importante la conciencia de la obra que estaba dejando.

Desde que nace en Fuendetodos, villorio aragonés vecino a Zaragoza, en 1746, hasta que muere en Burdeos en 1828, Goya nos repite siempre una vieja lección: el genio sólo se expresa plenamente tras el arduo trabajo y el concienzudo estudio. He aquí un problema muy de nuestra época. El excesivo auge academicista de principios del $\mathrm{XIX}$, en que se supeditaba la esencia a la forma, la expresión al tema, lo pictórico a lo literario o histórico, carga heredada de un neoclasicismo absurdo y decadente, trajo, por lógica consecuencia, una violenta reacción que, yendo en contra de todo lo académico, acabó llevándose de encuentro hasta los más elementales principios del conocimiento técnico. Surgieron los autodidactas y vino una época admirable, en lo que tuvo de búsqueda y de inquiietudo de valor morahpara decir las cosas, pero que, a muchos pintores, críticos y público llevó a confusión. Confusión que algunas veces "ondujo, al snobismo". Soy un convencido de la necesidad de la pintura moderna. Pero estoy más convencido aún de que para alcanzarla se requiere, como se ha requerido siempre en la vida - Y desgraciadamente nuestra época no ha podido mejorar nada en éso- estudio y trabajo. Aquí se ha expuesto creaçiones de dos grandes y universales artistas. Leonardo y Goya. $Y$ en sus obras hemos visto que han sido logradas con dos materias primas fundamentales: estudio y trabajo, claro que amalgamados con la esencia que mana del genio.

Goya, que borroneaba figuras desde niño, fué sorprendido pintando en una pared, a los catorce años, por el Padre Salcedo, Prior de la Cartuja de Aula Dei, y fué el dibujo tan del agrado del Prior, que, con la ayuda del conde de Fuentes, lo hizo ingresar en el taller de Luzán Martínez, de la ciudad de Zaragoza. Allí se hace aprendiz y, diariamente, durante seis años, adquiere del maestro Luzán los conocimientos que éste, a su vez, había logrado en Italia. Es verdaderamente impre- 


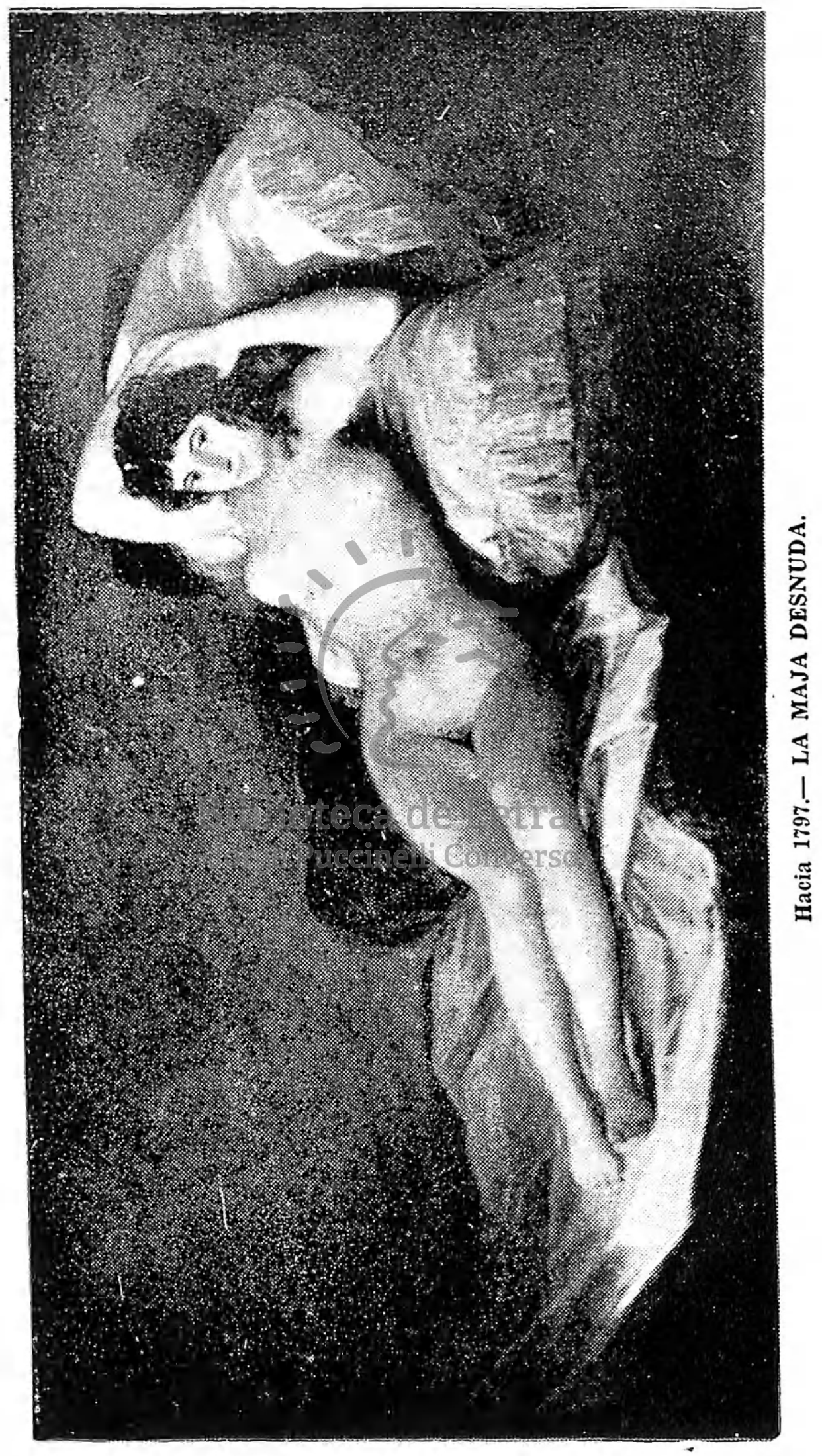




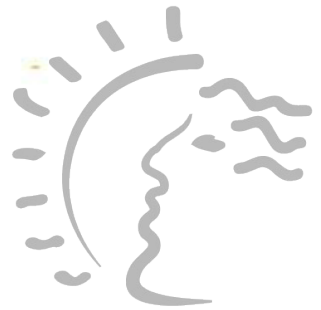

Biblioteca de Letras "Jorge Puccinelli Converso» 
sionante que, después de sesentiocho años de una labor indesmayable -pasan de mil sus obras- el viejo Goya ya consagrado, y que había aprendido lo que muy pocos privilegiados, nos deje en su último dibujo, la mejor frase de su testamento: "Aun aprendo".

El destino hace que Goya siga una vida que es ejemplo de luminosa trayectoria artística. Veremos así cómo empieza por empaparse en Roma de los viejos y permanentes modelos, que le dan solidez a su técnica, para retornar a su tierra, a embeberse en ella y extraer esa esencia que ha de procurarle conciencia de su genio. Así, al dejar el estudio de Luzán $y$, según cuenta Larraya, luego de haber fracasado en una de las oposiciones o concursos de la Real Academia de San Fernando, ganadas por su mediocre cuñado Bayeu, Goya viaja a Italia, comprendiendo que aún es incomprendido. Y lo hace ganándose la vida de una manera muy española, haciéndose personaje de aquel arte que luego inmortalizaría en sus aguafuertes de la Tauromaquia. Así, adentrado en lo popular, palpando y viviendo la tierra de sol y de sangre, de emoción y de tragedia, se diría que el joven pintor quiere llenarse de España, vivirla profundamente, para que aún lejos lo siga alimentando de angustia y rebeldía. Por eso Goya lleva en Roma una vida tan española. Hasta nació la leyenda de que preludiando al Don Juan de Zorrilla, hubo de dejar la Ciudad Eterna por haber querido raptarse una novicia de un convento. No quiere decir ésto que la vieja ciudad del Tiber, con sus siglos de tradición y de arte no influyera en él. Indudablemente que las obras de Tintoretto y de Tiziano le impresionaron, y sabemos también - nos dice Castán Palomar li que pocó antes de su marcha de Roma "trepó audaz, rápida y arriesgadamente, hasta la cúpula de San Pedro para -en gesto admirativo- estampar su firma en la gran obra de Miguel Angel".

Es curioso que sus biógrafos no hayan podido descubrir la vida o la obra de Goya en Roma, en la que según parece pasó más de un año. Se sabe sí que fué en Italia en donde trabó amistad con David, del que se acordaba hasta su vejez, pero de quien, sin duda, no recibió influencia alguna. Ni siquiera el cuadro de esa época "Aníbal pasando los Alpes", con el que ganara el segundo premio del concurso, organizado por la Academia de Parma, parece tener influencia de esta amistad, ya que el mismo Goya le expresa al pintar neoclásico, que trazaría la figura de Aníbal sin seguir la ruta de nadie. Era esa rebeldía e independencia hispana que siempre caracterizaría la obra goyesca. Y por designio genial, este pintor que no quiso seguir ninguna ruta, dejó muchas trazadas a los artistas que le siguieron. 
El triunfo que le había negado su propio país se le otorgaba fuera de él. No es la primera vez que ocurre. Y es al regreso de Italia, triunfante y acrecentado su prestigio, que sus paisanos le entregan, nada menos que su basílica del Pilar de Zaragoza, para que pinte la bóveda del coreto. España comienza a reconocer su mérito y la Junta que exa. minó su boceto, lo califica de "pieza de habilidad".

Aunque Goya era aragonés, más bien podría decirse, por qué Goya era aragonés y, por lo tanto, ibero, como dice Estarico: "menos imaginativo que los andaluces, más ágiles que los de Galicia, término medio entre los diversos extremismos de lo español, los aragoneses son los más representativos de lo ibérico" - hubo de viajar a Madrid, crisol del alma peninsular, para fundirse en él y convertirse en su pintor más representativo. Ya en su anterior viaje el joven, artista, había hecho su primera toma de contacto con la corte de Carlos III escudriñando un poco en el Madrid verbenero y castizo; el de las tertulias de la Fonda de San Sebastián, presididas por Moratín, en la que sólo se podía hablar de teatro, toros, amores y versos. Acaso aquí nació el gérmen que luego florecería en "La Tirana". La Tauromaquia, las majas y los líricos cartones.

Ahora Goya, triunfante y con la cara en alto y también hay que reconocerlo, con ciertas relaciones, en los altos centros pictóricos, pues se había casado con Josefa Bayeu, hermana de Ramón, que era pintor predilecto de quien entonces comandaba los rumbos estéticos de la corte, el afrancesado Rafael Mengst, sse afinca en Madrid. Por indicación de éste y conjuntamente con su cuñado] Ramón y el pintor Castillo, Goya es designado por Carlos III, en 1776, para que dé nuevo impulso a la Fábrica Real de Tapices. Contra los principios plásticos de Mengs y las ideas de Bayeu y Castillo, afrancesadas y neoclásicas, contra ese arte dirigido, Goya impuso, desde el primer momento, su afán libertario y romántico. Es lo que podríamos llamar, la primera época; la época romántica de Goya. Se esbozan así los síntomas de su romanticismo, y se muestra también, cómo el espíritu humano puede escapar a las coacciones del medio y luchar poco a poco, tenazmente, por la reinvindicación de la libertad artística, esencia de todo movimiento romántico. Movimiento que inspira a Víctor Hugo a querer un arte francés - que Madame Staél proclama indígena en Francia-y que Lamartine define al decir : "fuí el primero en hacer bajar la poesía del Parnaso y dar a lo que se ha llamado la Musa, en lugar de una lira convencional de siete cuerdas, las fibras mismas del corazón del hombre, rozadas y conmovidas por los innumerables estremecimientos del alma y de la Naturale$z a "$. Mas, Goya se había ya adelantado, desde el siglo anterior, en el 
menosprecio de los formalismos de un arte oficial, humedeciendo sus pinceles en la sangre misma del alma popular. Evolucionando lentamente y zafándose de influencias foráneas. De allí la diferencia que se nota entre sus primeros cartones de la merienda o el baile de San Antonio de la Florida y las posteriores de la Novillada o "El Pelele".

Goya tiene el mérito de unir en su obra, épocas diversas, pues si bien anuncia el romanticismo, conserva siempre, en su pintura genial, esencias de un arte, por lo general incomprendido: el barroco. No creo que el barroquismo de Goya, se deba a posibles influencias tiepolescas. Goya es barroco porque es apasionado y es apasionado porque es español. Gómez de la Serna, su barroco biógrafo, anota con acierto que "Goya palpita barrocamente y sus palabras ayudan a este barroquismo y todo él se revuelve en su pintura y abre brechas al tiempo, gracias, sobre todo, a lo que tuvo de barroco. El barroquismo es querer más de lo que se puede querer y ponerse a realizarlo sin haber acabado de hallar el camino y la manera, con ceguera genial y con deseo temerario. Quizás no haya manera de realizar la creación vital de los dioses; pero si de algún modo se puede ensayar, es con la barroquidad más que con la perfección ortodoxa".

Se pregunta uno ¿Es posible, entonces, ser barroco y romántico al mismo tiempo? Yo creo que sí, y Goya me da la razón. Lo que no es posible es ser barroco y neoclásico, o romántico y neoclásico, porque el neoclasicismo carece de lā llama que a aquellas alimenta, que es la llama de la libertad. Y ello es más posible en España, porque al pasar el barroco por las cálidas yaa yasionadas tierras ibéficas, dejó en ellas, como un sustratum que sigue iluminando el espíritu artístico que en ella florece.

Goya, heterogéneo y paradógico, es nombrado Académico de San Fernando el año de 1780. Su primer paso para convertirse en pintor de la corte. Se diría, entonces que va a enrumbar su paleta hacia el academicismo frí, flácido y complaciente. Y sin embargo, desde hace dos años y al establecer su primer contacto con el genial Velásquez, de quien graba un juego de sus obras y cuya contemplación le hace declarar "ante ésto, nada sé", están germinando en él las raíces del impresionismo. Por ello vamos a ver, poco después, que, al mismo tiempo que pinta un cuadro como el Cristo Crucificado, aún tímido en sus innovaciones, realiza el retrato del Conde Floridablanca y un poco más tarde su impresionista autorretrato ante el caballete. Es que Goya es como su pintura. Como se ha dicho: "hay una relación muy directa entre su arte y sus maneras personales. De súbito se irrita y parece que va a 
echar a perderlo todo, pero pronto se recobra y halla la solución justa. Sus iras son llamaradas que, repentinamente se extinguen. Así es su pintura, impetuosa en la concepción, llana en la ejecución, y calma, al terminarse".

Pero tal es su genio que a pesar de estas cualidades, defectos en los pintores de éxito social, logra triunfar con sus retratos ante la aristocracia madrileña y tras el éxito del concurso de San Francisco el Grande, es nombrado en 1786 Pintor del Rey. Para todo artista mediocre ello hubiera significado el triunfo y la meta de su carrera artística. Para Goya es recién el comienzo de su gloriosa trayectoria pictórica. Se inicia lo que podríamos considerar su segunda época, o período impresionista. No pretende ésta ser una división rigurosa con límites definidos, sino más bien una denominación, un poco valiente, con el fin de señalar, de alguna manera la evolución de sus conceptos hacia un arte cada vez más avanzado, más rico, más tremendo. Cumple los encargos de palacio, pero se salva del encasillamiento porque, como él mismo escribe a su amigo Zapater, emplea el tiempo sobrante, en hacer "cosas de su gusto".

Viene el año de 1788. Carlos IV, sucede al III y nombra a Goya pintor de Cámara con 50.000 reales de sueldo. Empiezan los encargos que él ejecuta, sin hipotecar la libertad de su paleta. Y así, el retrato del soberano en traje de corte o el de la Marquesa de Pontejo, no son para agradar, ni de un redismo formaly amanerado, sino retratos sicológicos. De una personalidad admirable se diría que sabe convencer a sus modelos de la necesidad de que queden en el lienzo tanto cualidads como defectos. A todos les dice su verdad y todos se la aceptan. Es todavía el crítico gentil, de buenas maneras, pero crítico siempre. Pinta sus personajes, podríamos decir, con amabilidad. No ha relucido aún el punzón que, en veces, mete dentro, de los pinceles. Así los delicadísimos retratos en gris de Tadea Arias de Enríquez o la Marquesa de la Solana y el sereno del Duque de Alba, contemporáneo del de su esposa Cayetana.

Es interesante señalar como Goya, que pinta siempre verazmente, trasluce, queriéndolo o nó, sus estados de alma y su pasión por la modelo. El primer retrato de doña María del Pilar Teresa Cayetana de Silva y Alvarez de Toledo, XIII duquesa de Alba, Marquesa de Villafranca, pintado en 1795, durante cuyas sesiones, se cree que nació el amor de Goya, nos muestra a la duquesa, - como se diría en Madriden "plan" de aristócrata. Rígida, la cabeza erguida y con una mirada fría y algo despectiva. Quizás, si tras de ella, se descubre a la Duquesa 


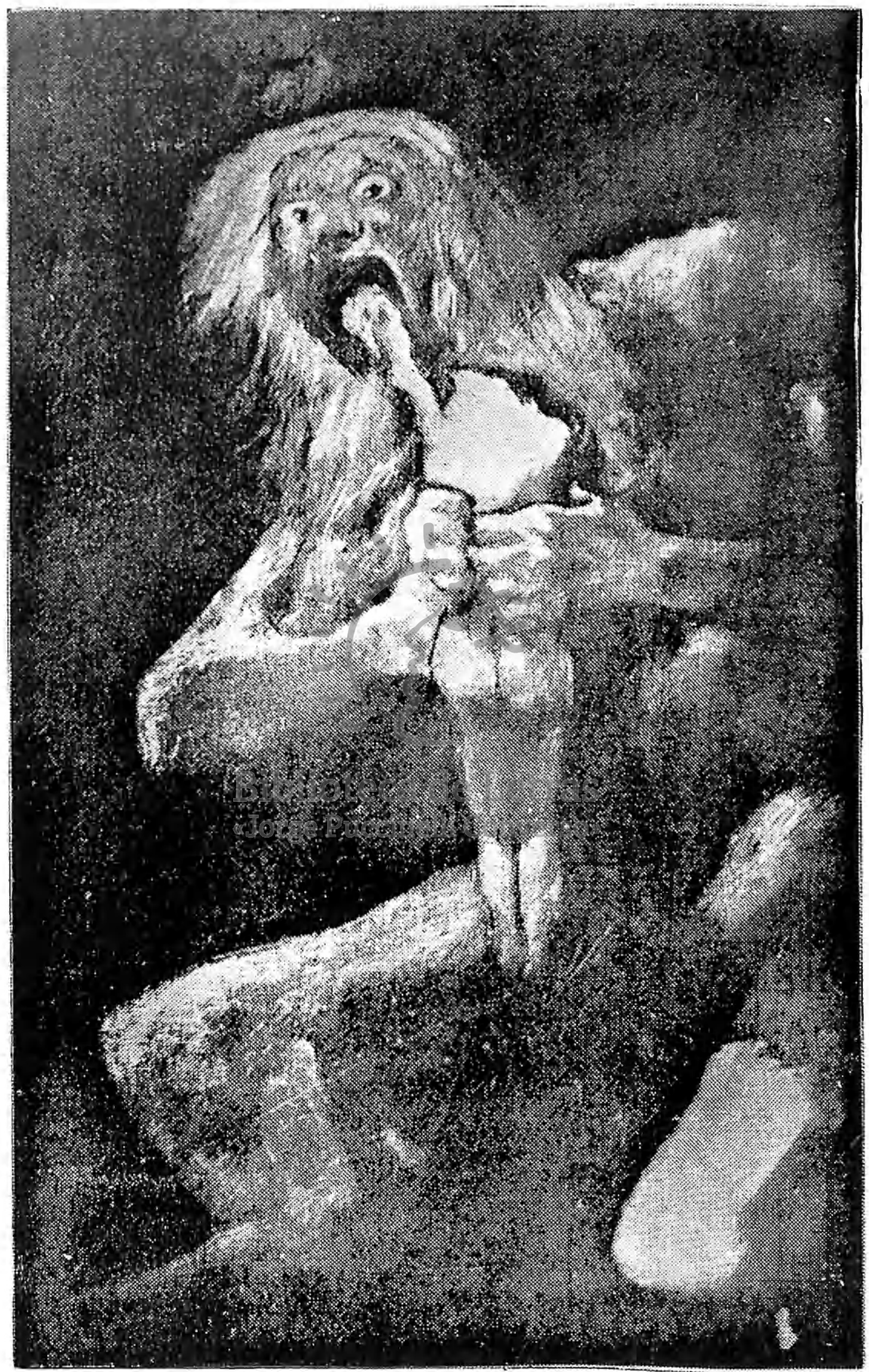

SATURNO DEVORANDO A SUS HIJOS

(pintura de la Quinta del Sordo). 


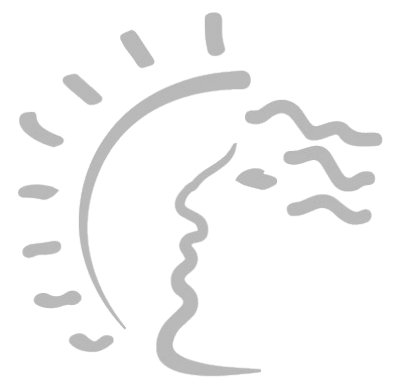

Biblioteca de Letras

"Jorge Puccinelli Converso» 
de Alba vestida de maja, aquella del segundo retrato, que pinta dos años después. Ya es la mujer, y nó los títulos, lo que predomina. Es la danzarina de fandangos, la chispera de Madrid, la alegría de las verbenas, cuyo rostro asoma tras la tan castiza prenda de la mantilla. Por ello la representa con la cintura quebrada y los piés dispuestos para la danza. En su tercer momento, Goya pinta a la Duquesa como "maja" desnuda. Se ha discutido mucho y se seguirá discutiendo, si la modelo es Cayetana. Los descendientes de Alba han gastado tantos esfuerzos en negarlo, como los críticos y poetas en afirmarlo. Nosotros estamos del lado de los poetas. Además, lo está Goya, pues en carta que escribe a su íntimo amigo Zapater, le dice : "Más me balía benirme a ayudar a pintar a la de Alba que se me metió en el estudio a que le pintase la cara, y se salió con ello, por cierto que me gusta más que pintar el lienzo, que también la he de retratar de cuerpo entero". Y la pintó de cuerpo entero. Vestida y desnuda. Y así retrata a la aristócrata, a la maja y, por fin, a la mujer. No importa que ésta esté con ropa o sin ella. En ambos está la mujer, la mujer desnúda, la mujer o el amor, la mujer o la pasión. Amor y pasión atributos de España y, por ello, de Goya.

También es atributo de España y, por lo tanto de Goya, calar en lo más hondo del ser humano, para extraer de él toda su verdad. Con crudeza, llamando al pan pan y al vino vino. No hay términos medios. El español es de extremos. Si hay que pintar un retrato, el pintor genuinamente español, -lo hace el Greco, lo hace Velásquez y lo hace Goya, cada uno a su maneratelo loplasma representandosal modelo en su totalidad física y anímica. De allí que Goya nos haya dejado una Reina María Luisa, que según se ha dicho parece un "faisán en vidriera de una tienda de ultramarinos", o una Infanta María Josefa que se la diría, una lechuza parchada. Pero en donde mejor se ha concentrado el sent1do crítico de Goya, es en aquel, su aristocrático aquelarre, titulado "La Familia de Carlos IV". De esa, "esperpéntica" familia que diría Ramón del Valle Inclán... No se trata, como se ha creído, de un cuadro pintado con un deseo de criticar la monarquía, exaltando los defectos de quienes en ese momento la encarnaban. Creo, más bien, con Juan de la Encina, que Goya, por no ser pintor cortesano, prescindió de la adulación y plasmó, como lo hacía siempre, lo que frente a él veía. A una familia afrancesada y decadente, que poco más tarde iba a ser descoronada. Con agudo sentido visionario, no retrata al grupo que gobierna un imperio, sino a una desdichada familia que vá, sin presentirlo, a un catastrófico final. Sólo el pintor, el genial pintor, oculto en la penumbra, 
imagina esos adornados muros palaciegos convertidos en lóbregas paredes de una casa de Bayona.

De asombrosa vitalidad, en el pináculo del triunfo, Goya sabe alternar el lienzo que revela a una aristocracia, insulsa y desvaída con cuadros de una emoción interna brutal. Tal el caso de "El prendimiento de Cristo". Muy pocos críticos han dado importancia a esta obrá. Ha pasado algo olvidada. Tal vez por el poco interés que se ha concedido siempre a la pintura religiosa de Goya. Gómez de la Serna se equivoca al decir que "todas sus escenas religiosas resultan de encargo, espolvoreadas de luz en rayos. Mezcla demasiado la luz al asunto religioso". Es verdad que no son muy religiosas, pero desde el punto de vista plástico son magníficos sus murales de San Antonio de la Florida - el cuadro de Toledo. Si es exacta la fecha que a éste se le asigna, de 1788 a 1789, constituye la primera manifestación definida de un Goya precursor del arte moderno. Es también el primer esbozo de su formidable pintura negra. Como ha dicho Lafuente Ferrari, el arte de Goya expresa, en profética anticipación genial, todo el proceso artístico posterior de la Europa ochocentista. En Goya, como en el arte propiamente moderno - también Rembrandt y Velásquez, supieron de ello, en su tiempo y a su modo- la pintura trata de evidenciar, de la manera más inmediata e intensa posible, con la mayor economía de procedimiento, la impresión que los objetos reales o imaginados nos dejan, fugaz, en el espíritu. El arte buscará el lenguaje propicio para esta traducción de impresiones en unailespecie de estenografía en la que esa economía de medios, que ahora se estima como esencial, logre mayor complejidad dentro de su abreviación. Supone todo ello el empleo de un lenguaje artístico escasamente respetuoso con la disciplina tradicional, y de aquí la lucha, que en el XIX va a plantearse abiertamente, entre la nueva manera de ver y la manera tradicional. Como hecho histórico ostensible esto no se manifestará claramente hasta la llamada batalla del impresionismo luchada en los medios artísticos de París, por los años 1860-1890. Pero para todos es evidente que todo esto se halla planteado y en parte resuelto, en la obra pictórica de Goya". El pintor aragonés, adelantándose a los impresionistas, clava el caballete al aire libre y se recrea pintando la pradera de San Isidro o la Procesión de los Disciplinantes o el Huracán, de la Colección del Jockey Club de Buenos Aires; y cuando más tarde viene la terrible época de la ocupación francesa sufre y se revuelve, eternizando las escenas de la Puerta del Sol o los fusilamientos de la Moncloa. 
El Goya libertario, el Goya indoblegable, el Goya que no ensordece ante el grito de su pueblo, el que siente profundamente la emoción social, porque todo lo ofrece y nada pide; el que se mezcla con el pueblo y alterna con los nobles, el que conoce las dos caras de la vida española, se rebela contra el invasor y con furia, a brochazos, pinta este cuadro que es toda una gesta libertaria.

Afirma Trueba, que con un catalejo en la mano derecha y un trabuco naranjero en la izquierda, desde una de las ventanas de la Quinta del Sordo, vió los fusilamientos de la Montaña del Príncipe Pío. Concibió mi amo, dice el jardinero de Goya, loco de indignación, la idea de pintar, aquellos horrores. Al acercarse la media noche, el pintor, le dice que tome su trabuco y lo acompañe a esa montaña donde aún palpitaban los cadáveres. Era una noche de claro-oscuro. La luna se asomaba de vez en cuando, como temerosa de ver tanta crueldad. Goya se sienta, abre su cartera y prepara su lápiz y cartón. Al fin la luna alumbra como si fuera de día y en medio de charcos de sangre aparecen, como fantasmas, los personajes que Goya perenniza y que van a dar comienzo a su primera estampa de los desastres de la guerra. Al preguntarle, al día siguiente su jardinero que por qué pintaba esa barbarie, Goya con un sentido maravilloso de su misión pictórica, contesta "para tener el gusto de decir eternamente a los hombres que no sean bárbaros".

A la vera del Manzanares, recluído en su Quinta, desde la que vé Madrid en perspectiva, entre el Puente de Segovia y el Pontón de San Isidro, volviendo a la tierra, como buen aragonés mejor dicho alejándose de una civilización, cada vez menos civilizada, y cuyo progreso lleva a parejas su barbarie, Goya inicia lo que podríamos llamar su tercera época : su época expresionista. No le preocupa ya, como antaño, el juicio ligero o la alabanza mundada. El sabe, que sabe más que los demás, pues ha descubierto que se puede triunfar pintando lo que uno vé y siente, y no lo que los demás quieren que uno vea y sienta. Plasmando la verdad, sea ella bella o fea, que, desgraciadamente, la verdad no siempre es hermosa. Expresando todos los aspectos de la realidad humana -el moralista inmoral, le llama Eugenio D'ors- pintando lo bueno y lo malo de ella, que muchas veces más tiene de ésto que de aquello. Y éste es para mí el mayor mérito de Francisco de Goya y Lucientes, ser posiblemente el primero, que se decide a no pintar bonito sino a pintar lo verdadero, a alejarse de todo "arte oficial", a romper la tradición del molde clásico, a quebrar la forma cuando lo requiere la expresión o cuando se lo impone su emoción. Una vez más, se com- 
prueba, de cómo los hombres geniales se anticipan a su tiempo. El, esencialmente pintor, comprende que una época como aquella borrascosa, inestable, en que la guerra hace romper tantos principios y en la que el mundo se estremece, con la revolución francesa, buscando un nuevo equilibrio, no es posible seguir pintando frívolas escenas a lo Watteau, frias epopeyas a lo David o acartonados y dulzones retratos a lo Mengs. La revolución se expande por el mundo, no solamente en el aspecto político y social, sino en el fuero interno del hombre. Y Goya, sordo y alejado en la ribera del Manzanares, oye, sin embargo la clarinada, y la estampa, callado, revolviéndose en sí mismo, se diría que a golpe de puños, en su famosa pintura negra de los muros de su quinta. Pintura que se adelanta un siglo, y que nos revela al Goya, visionario, rebelde y obstinado. No pintó Goya "Pour epater le bourgeois". Pinta para él, aunque en realidad pinta para la historia. No es su pintura negra, cuadro preparado para salón de Independientes, por el contrario, la estampa en un lugar solitario, alejado. En su casa. Sin alardes, ni escándalos. Quizás si tan famoso mural no habría llegado hasta nosotros, de no haber sido por el Barón alemán Emilie D'Erlanger, posterior propietario de la Quinta del Sordo, quien en 1873 dispuso que las catorce pinturas, distribuídas seis en el comedor y ocho en el salón de la planta principal, se arrancasen y pasasen a lienzo, para ser expuestas en el Palacio del Trocadero de la Exposición de París, siendo luego, en gesto admirable y ejemplar tobsequiadas al Museo del Prado.

¿Qué es esta terrible pintura negra dé Saturno devorando a sus hijos, de la Manola o de las "Visiones de la romería de San Isidro"? Desde el punto de vista estético, señala Estarico, estas pinturas son la obra cúspide del maestro. "Ni esquematismo descarnado, ni escorzos o deformaciones grandilocuentes. Plástica, simplemente plástica, pero plástica sublime, plástica hecha espíritu, en el soplo mágico del taumaturgo". Lafuente Ferrari, manifiesta que son extrañas pinturas, de un desenfrenado expresionismo, culminación del aspecto demoníaco y tenebroso de la imaginación goyesca. Mayer, luego de referirse a los cuadros la "Aguadora" y el "Alfiler" del Museo de Budapest, de un modernismo sorprendente, dice : "Pero lo más gigantesco siguen siendo aquellas decoraciones murales con que el solitario decoró su casa, tan lúgubres en apariencia y color, inexplicables a menudo en su significación, - yo creo que son explicables pues no explican un tema sino a un hombre, al pintor- pero gigantescas, semejantes a grandes fantasmas que aparecen en sueños, fuerzas elementales que se revelan sólo a la mirada 


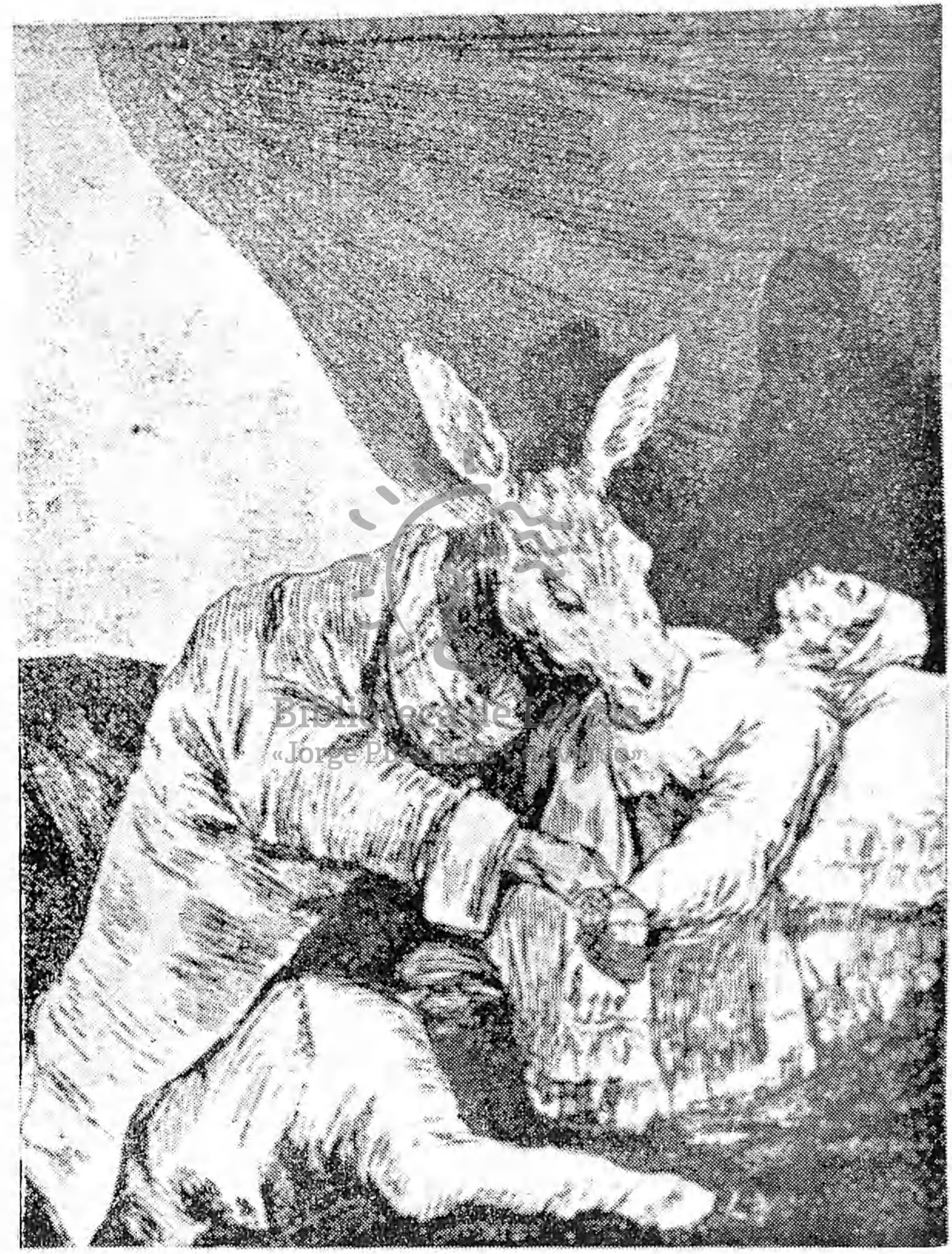

LOS CAPRICHOS : “¿EE QUE MAL MORIRA?” (aguafuerte y agua tinta). 


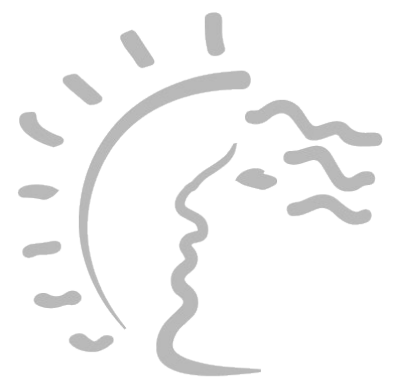

Biblioteca de Letras

"Jorge Puccinelli Converso» 
interior y que ascienden del reino de la naturaleza a la imaginación de los grandes poetas". Para Gastón Palomar: "Aquellos grandes trazos dramáticos, furiosos, doloridos, exasperados, pero como una burla de lo dramático, de la furia, del dolor y de la exasperación, hacen del costumbrista un visionario". Figuras espantosas, de una época cruel que saca al artista de juicio, dice Elie Faure. Gómez de la Serna lleva su admiración por Goya, hasta el extremo de considerar estas pinturas como: "el "Juicio Final", de un hombre más soterreño que Miguel Angel, con las mismas contrastaciones y empalustres de negruras y claridades, sino que más humano y al nivel del mundo". Mas, no todos sus biógrafos han comprendido el genial anticipo pictórico de Goya. Así Beruete, supone que las pinturas negras pudieron haberse realizado con intención de asustar y embromar al impertinente visitante. Y Juan de la Encina, destaca en ellas, un carácter grotesco, que yo no encuentro. Goya no busca asustar a nadie, ni expresar lo grotesco. Estos murales son más bien explosiones de desahogo. El artista es un hombre, tan lleno de tensión, y de vida interior, que si cada cierto tiempo no suelta todo lo que le bulle dentro, estallaría. Esa su rica vida interior, le lleva a hurgar en todos los campos y a sentir todas las inquietudes. Sordo, aislado, triste - de veinte hijos sólo logró uno- decepcionado en el amor, impresionado por la guerra que le rodea y que ha destruído su tierra de Aragón, cercado por el fuego y la sangre, el terror y el odio, responde a la vida y a los hombres cón zarpazos de fiera acorralada.

"El sueño de dāorazón produce imonstruos" ${ }^{\prime}$ " He aquí una frase, tantas veces citada, pero que no puede olvidarse porque retrata su estado de alma en esos momentos. Así, primero es el gran desahogo de Los Caprichos, luego el de Los Desastres, más tarde el de la pintura negra y, por último, el de Los Proverbios o Disparates. En todas estas obras aparece ese subconsciente goyesco, atormentado y terrible, de gran "adelantado" de la pintura moderna. No falta así tampoco su faceta "superrealista", inspirada, quizás, en las obras que pudo apreciar en ese otro gran precursor del superrealismo: Jerónimo Bosch, ○ El Bosco. Este, más que Brueghel, inducirá al inquieto aragonés hacia los campos oníricos. Payró ha definido el superrealismo como una tentativa de explorar la subconsciencia y evocar reacciones emotivas por medio de la yuxtaposición ilógica de objetos y formas humanas no coincidentes. Entonces, ¿No es superrealista aquel Capricho, titulado, "Ya tienen asiento", en que aparecen unas figuras femeninas con una silla sobre la cabeza? '¿O el titulado : Contra el blen general", en que se vé a un 
viejo con orejas aladas? ¿O aquel otro "Disparate volante", cuyo super. realismo se basa, precisamente, en el profundo realismo español?

No he querido referirme a la obra grabada de Goya, ni a sus dibujos. En este mismo salón hemos oído ya en torno a ello autorizadas voces de destacados conferenciantes. Mas sí deseo hacer breve hincapié, en un aspecto original de su personalidad, que muy pocos han visto y que está de acuerdo con su psicología de hombre moderno, aquel que denota un indudable sentido periodístico. No crean ustedes que a ello me mueven razones de índole personal motivadas por mi profesión. No es tampoco originalidad mía, ya Gómez de la Serna, anota en su biografía de Goya que, "Sus Caprichos" son periodismo, comentario y amenidad, contraste de lo real con lo imaginado, flotante sátira fácil de reproducir, escrito ya en ella el "pie" de la publicidad, el "pie" periodístico, corretón, sobrentendido, trazado con letrâs veloces. Hasta en sus cuadros episódicos sobre fabricación de pólvora y la persecución de un asesino, descrita en varias viñetas, siente la necesidad de perpetuar lo que suceda como anécdota periodística de la vida. La primera caricatura política y moral de la época está en sus aguafuertes".

Yo voy más allá; no creo que sólo en sus Caprichos o en algunos cuadros episódicos se manifiesta este sentido periodístico de Goya. Si nos detenemos a pensar, el maestro aragonés, escoge casi siempre en sus cuadros, salvo en el género del retrato o en el religioso, "temas" de actualidad. Verdad que en los primeros tapices, estos le fueron dados, pero luego él se imponegy pintainol sólo hechoso de la vida real, sino sucesos del momento, que seguramente merecieron el comentario público, tales como "La riña en la venta nueva", o "El albañil herido". Se puede decir que existe ya en él preocupación por lo que podríamos llamar la "noticia ilustrada"; ello se deduce de esa serie de cuadritos, del año 1806, en que describe la captura del ladrón Maragato, por un fraile franciscano, en plena calle madrileña. Son cuatro cuadros, en los que se anota los varios momentos del suceso. Desde que el hermano sujeta el arma del ladrón, la lucha por la posesión de la escopeta, hasta que éste es maniatado y viene la gente en su ayuda. He allí una noticia interesante. Un tímido sacerdote enfrentándose a un peligroso hampón.

¿No es tener sentido periodístico, escoger temas que se refieren a la vida diaria del pueblo; danzas, juegos, verbenas, meriendas o procesiones? ¿O a personas que gozan de popularidad, como la célebre artista La Tirana, el torero Pedro Romero, el actor Isidro Maiquez, o el comediógrafo Moratín? ¿O a anécdotas o hechos que constituyen el comen- 
tario público, como la muerte de Pepe Illo, las locuras de Martincho y del limeño Mariano Cevallos, el entierro de la sardina, el tribunal de la inquisición, o la procesión interrumpida por la lluvia.....? 'Temas periodísticos por cierto, aún en la actualidad, son, reproducir el "Interior de una casa de locos", "El incendio de un hospital", "La inundación", "El interior de una prisión", o "El toro acometiendo a una procesión". Pero hay algo más importante en el periodismo, que relatar hechos y es, el encauzar y orientar la opinión pública, a través de una línea moral y libre. Precisamente, es esa libertad de expresión y de crítica, la que usa Goya para comentar los sucesos que conmueven su ciudad o para censurar duramente los vicios que la aquejan. Y para ello, se vale del dibujo humorístico, o sea de la caricatura, forma periodística que se empleaba ya, en el siglo XVIII, en América, por Benjamín Franklin, en "The New England Courant". Mas el genio de Goya, por más que Baudelaire, considera que el pintor español no sea ante todo sino un mago de la caricatura, va más allá de ella, pues no sólo ridiculiza el hecho o la persona, sino que, al destruír, construye, porque marca el sendero de la verdad. Porque muestra al público lo que está mal y, poniendo el dedo en la llaga, valientemente y sin temor a censuras o castigos -tal el caso de los desastres de la guerra- pinta la barbarie y señala al pueblo el camino de lo heroico y de la libertad. Con un alto sentido de justicia condena la brutalidad del invasor y los desbordes del populacho. Es por cierto, por último, lafán del moderne periodista, relatar, gráficamente, los hechos. Goya habría sido un genial feporter gráfico. Lo demuestran las mismas leyendas de sus grabados, como aquel en que atestiguando su presencia en el lugar de los sucesos, dice: "Yo lo ví". Y vió también, con un catalejo, los Fusilamientos de la Moncloa y, guiado por ese su sentido de relatar lo que veía, lo más fielmente posible, coge una linterna, y en una noche de luna, asciende a la Montaña del Príncipe Pío, para allí, entre los cadáveres, fresca aún la sangre, realizar una genial información para la historia.

Grave enfermedad tuvo Goya en 1819, pero su tosudez aragonesa, pudo más que la muerte. Recobrada la salud, retoma los pinceles y vuelve a estampar en el lienzo magníficos retratos, como el de Tiburcio Pérez o Ramón Satué, demostrativos de que aquello de su pintura negra era un desahogo. Pues vuelve al género del retrato, al retrato sicológico, como los anteriores, y cáustico y mordaz como el de Fernando VII en traje militar. Es el Goya de siempre. El Goya zigzagueante de Juan de la Encina, que nos deja un óleo como la Comunión de San José de Calazans, tímido en su impresionismo y una imponente Oración del huerto, 
en que vuelve a jugar con el claro-oscuro como lo hiciera Rembrandt, pintor a quien tanto admira. Aún fuera de España, cuando tiene que viajar a Francia, bajo el pretexto de su salud, pero según se dice por sus ideas liberales, o por no sentirse asqueado de la represión contra sus amigos los constitucionales, sigue trabajando. En Burdeos y a los 78 años todavía pinta. Tiene su tertulia con Moratín y otros liberales y alterna el apunte con el óleo o la litografía. De esta época son los famosos "Toros de Burdeos", bello corolario de su no menos famosa serie de la Tauromaquia. Ha pasado los ochenta años y sigue pintando. Seguirá pintando hasta la muerte, porque hay algo que en él no se marchita. Es su espíritu. Su espíritu indomable e indesmayable, de aragonés tenaz, que no admite derrota. Y lo seguirá haciendo, a su manera, sin mermar sus facultades y expresando on cada cuadro, su múltiple y genial personalidad. A los 81 años pinta su último retrato; el de don José Pío de Molina. Tal obra ha sido considerado como el testamento artístico de Goya, porque en ella ha resumido su trayectoria pictórica que anuncia una vez más y marca el primer hito de la escuela naturalista impresionista. Aunque yo me inclino a creer que ello lo realiza un año antes en su impresionista e impresionante autorretrato del Museo de Boston. Por curiosa coincidencia es en la misma Francia, tierra en que han de plasmarse los grandes movimientos de la pintura moderna, tales como el romanticismo, impresionismo, expresionismo o superrealismo, donde un viejo pintor de una aldea aragonesa, anunciador de todos estos "Ismos", dejará su paleta, como un símbolo de que allí brotarían los frutos des su vital simiente, anunciadora de nuevos mensajes de belleza.

Moría su cuerpo. Se enterró en Burdeos. Y al ser trasladado a España, a su Madrid, tan bellamente cantado por sus pinceles, se descubrió que la cabeza del maestro había desaparecido. Se dice que un estudiante de frenología la robó para estudiar en ella las características del genio. Pero creo que se equivocan. Y quiero que se equivoquen. La cabeza de Goya debía desaparecer, porque tenía una misión que cumplir, la de convertirse en símbolo. En símbolo de la búsqueda y de la inquietud. El misterio que rodea su destino, es el misterio que rodea al destino de la pintura moderna. La inquietud y la búsqueda, la tensión y la emoción, el valor y la crudeza, la prescindencia de convencionalismos y la ruptura de caducos moldes académicos, que caracterizan a la pintura contemporánea, fueron los impulsos que nacieron en esa cabeza. Se perdió el cráneo pero quedó vivo el aliento que ilumina a todo aquel que siguiendo su ejemplo se decide a pintar con verdad. $Y$ es ésta su gran lección. Aquella de pintar para sí antes que para los 
demás. Aquella de plasmar lo que se siente y se cree. Aquella de volcarse en la creación plástica. Aquella de buscar inquietamente en todos los caminos, para ver cuál es el sendero de su verdad. Y aquella de trabajar, trabajar incesantemente con el ansia de alcanzar la perfección. Aquella de olvidar el éxito fácil y fugaz, conseguido al través do la concesión o el escándalo. Aquella, por último de pintar con el alma y para el alma.

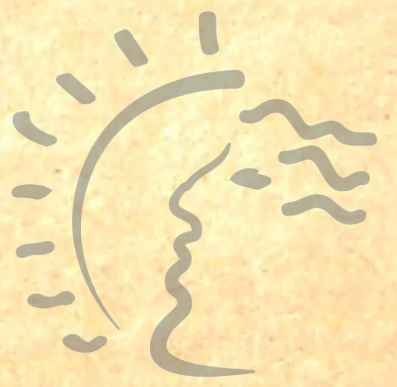

\section{BibliotecadeIetras}

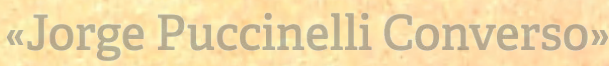

